\title{
CHARGE DENSITY CHANGE IN THE VITELLINE SURFACE FOLLOWING FERTILIZATION OF THE RABBIT EGG
}

\author{
G. W. GOOPER AND J. M. BEDFORD \\ Department of Anatomy, Columbia University, \\ College of Physicians and Surgeons, New York 10032, U.S.A.
}

(Received 4th August 1970)

\begin{abstract}
Summary. Fertilized and unfertilized rabbit eggs, devoid of the zona pellucida, were exposed at $\mathrm{pH} 1.8$ to a suspension of positively charged ferric colloid particles. The vitelline surface of the fertilized egg invariably bound a greater number of these electron-dense particles per unit area than did the surface of the unfertilized egg. Changes in the rabbit egg associated with sperm penetration appear to involve an increase in the concentration of negatively charged groups at the egg surface. Variation of the $\mathrm{pH}$ of reaction, and analysis with purified neuraminidase before and after saponification with $\mathrm{KOH}$, suggests that, at $\mathrm{pH} 1 \cdot 8$, these negative groups are contributed by carboxyl radicals of surface sialic acids present in the $\mathcal{N}$-acetyl- $O$-diacetyl configuration. The findings are discussed briefly with reference to the block to polyspermy and sperm/ egg attachment.
\end{abstract}

\section{INTRODUCTION}

Studies of the fertilization process in mammals and in non-mammalian species indicate that the interaction of the fertilizing spermatozoon with the vitelline membrane induces a change in the character of the egg surface. This surface reaction, stimulated by the fertilizing spermatozoon, apparently renders the egg plasma membrane refractory to the entry of other spermatozoa and provides a block to polyspermy. The block at the vitelline surface is particularly important in the rabbit egg which does not develop any significant reaction at the level of the zona pellucida. However, in some other species, e.g. hamster and $\mathrm{dog}$, the zona pellucida undergoes changes in response to penetration which render it refractory to succeeding spermatozoa (see Austin \& Walton, 1960). The lethal implications of polyspermy for the embryo have been reviewed in recent years by Rothschild (1954), Beatty (1957) and Piko (1961).

The rupture to the exterior of cortical granules within the egg has been observed to take place more or less coincidentally with fusion of the fertilizing spermatozoa and vitelline membrane both in mammalian (Szollosi, 1967) and in non-mammalian eggs (see Austin, 1968). This cortical reaction is probably completed within a few seconds in invertebrate eggs which are exposed to large 
numbers of spermatozoa at spawning. In mammals, on the other hand, relatively few spermatozoa are present at the site of fertilization in the tubal ampulla suggesting that there may have been less selection pressure for such rapid completion of the cortical response in mammalian eggs. Indeed, in studying the morphology of sperm penetration into the ooplasm, one of us (J.M.B.) has observed cortical granules in the process of dehiscence when the fertilizing spermatozoon had fused with and had partly been engulfed by the egg, i.e. several minutes after initial contact of the spermatozoon with the vitelline surface. The readiness of cortical granules to stain with ruthenium red (Szollosi, 1967) suggests the presence of polysaccharide in these granules, and other evidence indicates they may be lysosomal in nature (see Stefanini, Oura \& Zamboni, 1969).

Little is known of the general nature of the change which occurs in the egg plasma membrane during the 'vitelline reaction'. Demonstrations of change in the electrical resistance of this membrane after fertilization of starfish eggs (Tyler, Monroy, Kao \& Grundfest, 1956), and in the light refracting property of the cortex in sea urchin eggs (Runnstrom, 1928; Rothschild \& Swann, 1949) imply that significant changes in the quality of the limiting plasma membrane do occur at this time. Apart from observation of the rupture of cortical granules and incorporation of their membranes into the egg surface, there is no direct evidence of modification of the vitelline surface of mammalian eggs at fertilization, although the general absence of polyspermy and the failure of motile supernumerary (perivitelline) spermatozoa to adhere to the vitelline surface suggest the occurrence of like changes in the vitelline surface in mammalian eggs.

In the present study, we have approached this problem using the technique developed by Gasic, Berwick \& Sorrentino (1968), in which the surface in question is exposed to a suspension of positively charged ferric colloid. Using this method with the electron microscope, we have been able to visualize a consistent change in the density and pattern of distribution of negatively charged groups at the vitelline surface of the rabbit egg as a consequence of sperm penetration.

\section{MATERIALS AND METHODS}

Unfertilized rabbit ova were recovered from donor females which had received 50 i.u. HGG 13 to $14 \mathrm{hr}$ previously, by flushing their excised Fallopian tubes with Ringer solution. Fertilized ova were recovered likewise, usually 14 to $15 \mathrm{hr}$ after mating of an oestrous donor doe with two fertile males. The likelihood of fertilization in these ova was assessed by observation with a dissecting microscope, taking into account the presence of mobile supernumerary spermatozoa and the appearance of two polar bodies in the perivitelline space, together with a central pale area in the ooplasm which reflects the presence of developing pronuclei. Eggs which did not satisfy these criteria were discarded. For study of the morphology of the cortical granules, whose eggs were immersed in $2.5 \%$ glutaraldehyde in collidine or phosphate buffer for $1 \mathrm{hr}$, after which they were fixed in $1 \% \mathrm{OsO}_{4}$ in $0.1 \mathrm{~m}$-phosphate buffer at $\mathrm{pH} \mathrm{7.4}$. After dehydration in 
alcohols and propylene oxide, followed by embedding in Epon 812, thin sections of these intact ova were stained with lead citrate and uranyl acetate.

For studies of the pattern of negatively charged ionized groups at the vitelline surface, the zona pellucida was removed from fertilized and unfertilized eggs with sharp dissecting knives after it had been hardened by brief fixation in $2.5 \%$ buffered glutaraldehyde. After fixation for $1 \mathrm{hr}$ at room temperature in $2.5 \%$ glutaraldehyde in $0.1 \mathrm{M}$-phosphate buffer, at $\mathrm{pH} 7 \cdot 4$, the eggs were washed once in phosphate buffer and then in distilled water. The denuded ovum was then exposed to a suspension of positively charged colloidal ferric oxide particles prepared according to Gasic et al. (1968). For this purpose, a stock solution of undialysed colloidal ferric oxide was prepared in advance, and staining was performed with a freshly prepared mixture of $10 \mathrm{ml}$ of the stock colloid to which was added $10 \mathrm{ml}$ glacial acetic acid and $20 \mathrm{ml}$ distilled water. The $\mathrm{pH}$ of this staining solution was then adjusted to 1.8 with $1 \mathrm{~N}-\mathrm{NaOH}$.

In all cases, eggs were exposed to the colloid solution for $10 \mathrm{~min}$, and then washed in $12 \%$ acetic acid, and in distilled water, before post-fixation in $1 \%$ $\mathrm{OsO}_{4}$ in $0.1 \mathrm{~m}$-phosphate buffer at room temperature for $1 \mathrm{hr}$. Dehydration was carried out in a graded ethanol series and in propylene oxide, and the eggs were embedded in Epon 812.

The chemical identity of the molecules bearing the negatively charged surface groups at $\mathrm{pH} 1.8$ was investigated by neuraminidase treatment (Marikovsky \& Danon, 1969). In the first instance, eggs were treated with chromatographically purified neuraminidase (Type VI, Clostridium perfringens-Sigma) for $1 \frac{1}{2} \mathrm{hr}$ at $37^{\circ} \mathrm{C}$, at a concentration of 2 units $/ \mathrm{ml}$ in Eagle's medium adjusted to $\mathrm{pH} 6.5$ with $\mathrm{CO}_{2}$. Subsequently, the fixed and washed eggs were saponified with $0 \cdot 1$ $\mathrm{N}-\mathrm{KOH}$ for $30 \mathrm{~min}$ at $37^{\circ} \mathrm{C}$ (Ravetto, 1968), after which they were incubated in Eagle's medium alone or with the neuraminidase. The eggs were then washed once in distilled water, exposed to the ferric colloid solution and processed as described above. Examination of the binding characteristics of the surfaces of the different eggs, as reflected in surface deposition of the charged particles, was carried out with a Phillips 200 electron microscope.

\section{OBSERVATIONS}

Sections of the normal unfertilized rabbit egg reveal irregularly spaced cortical granules lying immediately below the vitelline surface (Pl. 1, Fig. 1). Such a picture is invariably seen in the newly ovulated rabbit egg and contrasts with the mouse egg, in which many of the granules apparently form and move from the interior toward the egg surface in the hours immediately following ovulation (Zamboni, 1970).

Exposure of the denuded unfertilized egg to ferric colloid at $\mathrm{pH} 1.8$ resulted in a relatively modest degree of binding of the positively charged electron-dense colloid particles to the vitelline surface (Pl. 1, Fig. 2). When the $\mathrm{pH}$ of this reaction was reduced to $1 \cdot 0$, such binding no longer occurred, indicating the absence of any negatively charged groups on the vitelline surface at this low $\mathrm{pH}$.

Interaction of the fertilizing spermatozoon with the plasma membrane of the unfertilized egg stimulates the rupture and release of the content of the cortical 
granules into the perivitelline space (Pl. 2, Fig. 3). The limiting membrane of the granule appears to fuse with and become incorporated as part of the surface of the fertilized egg in the manner described by Szollosi (1967) for the hamster and rat. When denuded fertilized eggs which had completed this cortical reaction were exposed to the ferric colloid suspension, this resulted in the surface binding of particles at a much greater density per unit area (Pl. 2, Fig. 4) than on the unfertilized egg (Pl. 1, Fig. 2). Moreover, whereas the colloid deposition on the unfertilized egg in general followed the visible outline of the egg surface rather exactly, that on the surface of the fertilized egg appeared as a multilayered deposition extending superficially beyond the visible limit of the surface.

The possibility that the negative charge on the vitelline surface, at $\mathrm{pH} 1.8$, was contributed by surface sialic acids, as suggested by the work of Marikovsky \& Danon (1969) on red cells, was investigated by the use of purified neuraminidase preparations. Exposure of the denuded, untreated, vitelline surface to this enzyme produced no significant change in the negative charge density on the surface of either unfertilized or fertilized eggs, nor was any change seen following saponification treatment with $\mathrm{KOH}$. When the saponified unfertilized and fertilized ova were treated with neuraminidase, however, essentially all the negative groups ionized at $\mathrm{pH} 1.8$ were removed, as judged by the virtual absence of any ferric colloid particles bound to the treated egg surface at this $\mathrm{pH}$. However, this treatment did not change the appearance or continuity of the vitelline membrane.

\section{DISGUSSION}

The technique of Gasic et al. (1968), used in this study, demonstrates the relative density of negatively charged groups on a cell surface. In this reaction, positive electron-dense ferric colloid particles are believed to be attracted and bound to negative radicals at the surface by simple electrostatic forces. Since the colloid particles differ somewhat in size, and since it is not clear how many negative groups are required to bind a particle effectively to the surface, it is not possible to calculate accurately the density of ionized radicals per unit area. On the other hand, the technique does easily allow comparison of the relative density and distribution of negative charge on the surfaces of different cells under given conditions. Glutaraldehyde, used to stabilize the cell during the reaction, masks free surface amino groups. For this reason, it has not been possible to measure the positive element in the charge mosaic at the cell surface. Only relative charge density can be considered and not the net negative charge or the zeta potential at the surface.

In this study, at $\mathrm{pH} 1 \cdot 8$, the vitelline surface of the fertilized rabbit egg bound a greater number of ferric colloid particles per unit area than did the surface of the unfertilized egg (cf. Pl. 1, Fig. 2 and Pl. 2, Fig. 4). We interpret this observation as evidence of change in the vitelline surface resulting from sperm penetration and involving an increase in its negative charge density. It is not clear whether this change occurs immediately upon contact of the spermatozoon with the egg surface, or only as a consequence of the rupture of the cortical granules. 
PLATE
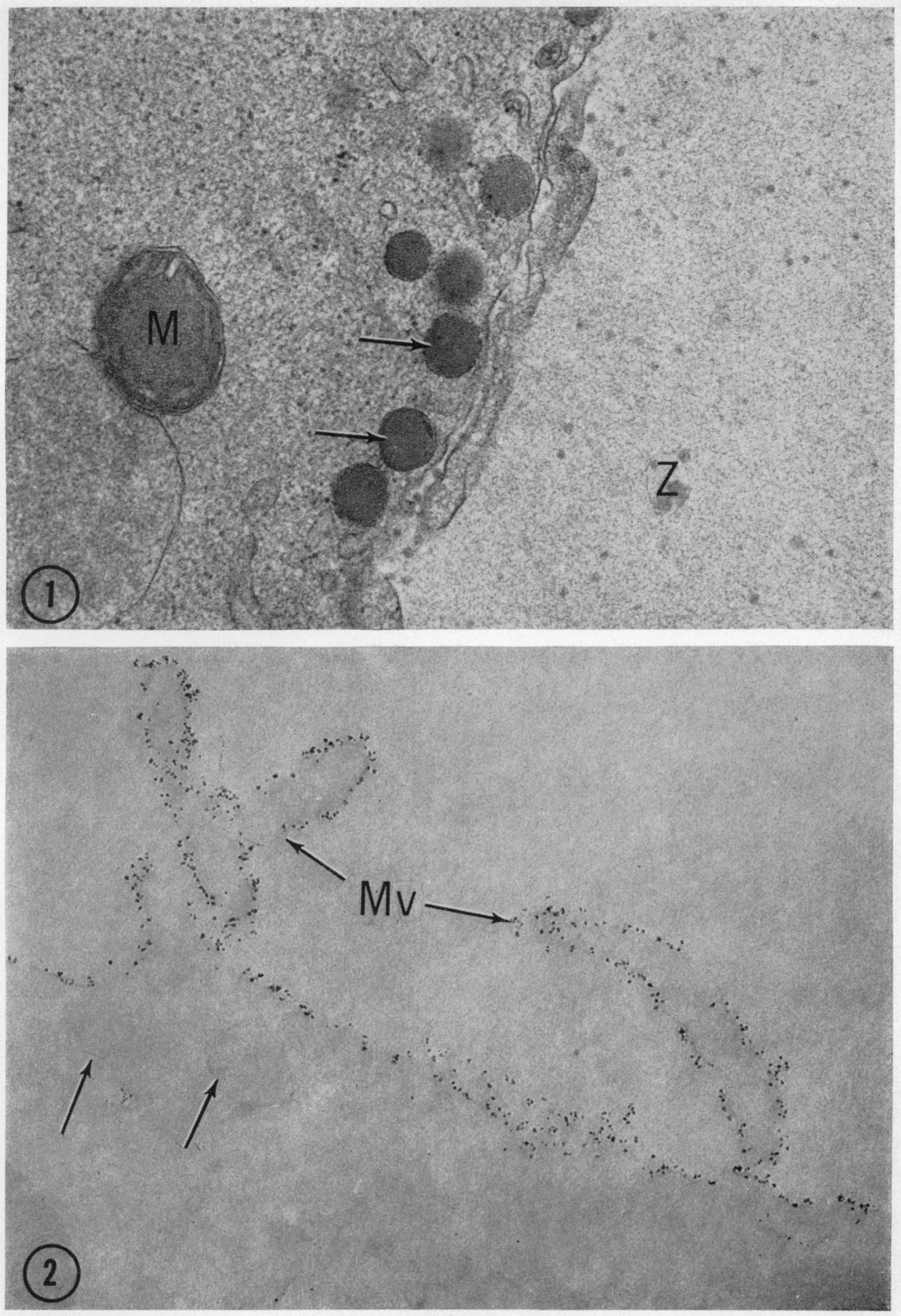

Fig. 1. Section of unfertilized rabbit ovum recovered 2 to $3 \mathrm{hr}$ after ovulation, showing intact cortical granules (arrowed) lying beneath the vitelline surface. $\mathrm{M}$, mitochondrion; $\%$, zona pellucida. Uranyl acetate and lead citrate. $\times 28,000$.

Ficr. 2. Section of unfertilized rabbit ovum (unstained) recovered 2 to $3 \mathrm{hr}$ after ovulation and exposed to ferric colloid suspension. Note the relatively modest degree of binding of ferric colloid particles to the vitelline surface (cf. Pl. 2, Fig. 4). Arrows indicate the outline of intact cortical granules. $\mathrm{Mr}$, egg microvillus. $\times 45,000$. 

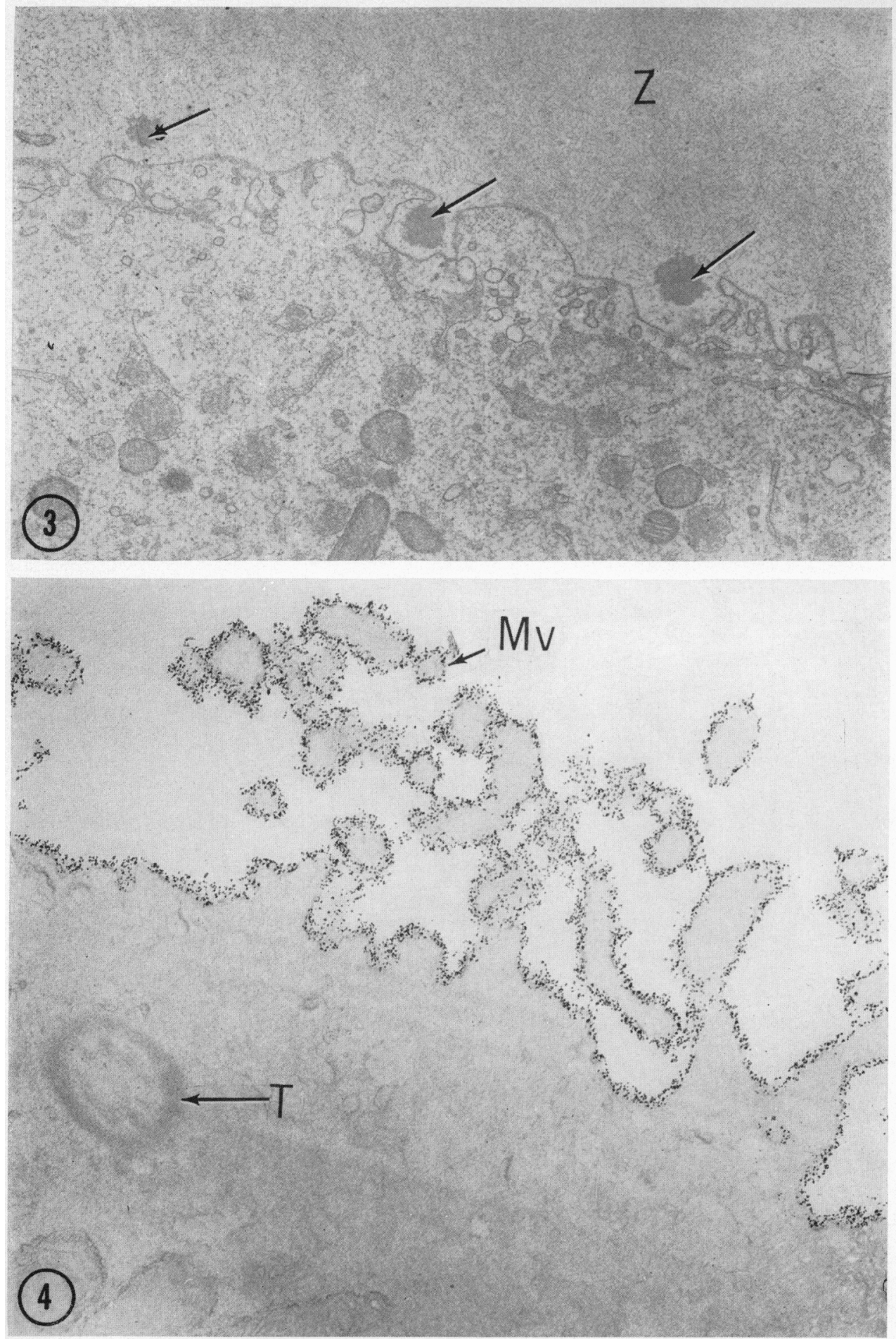

FIG. 3. Section of the surface of rabbit egg showing the moment of rupture of the cortical granules (arrowed) which occurs as part of the 'cortical reaction'. Z, zona pellucida. Lead citrate and uranyl acetate. $\times 24,000$.

FIG. 4. Section of fertilized rabbit egg (unstained) recovered 2 to $3 \mathrm{hr}$ after ovulation. This egg, exposed to ferric colloid suspension after completion of the cortical reaction, shows colloid particles bound to the vitelline surface as a multi-layered deposit, at a much

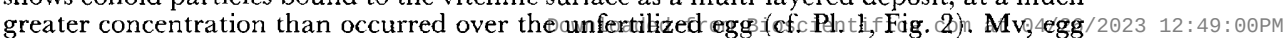
microvillus. $\mathrm{T}$, tail of fertilizing spermatozoon. $\times 39,000$. 
Although the present reactions occurred at $\mathrm{pH} 1 \cdot 8$, it seems likely that the observed increase in negative charge density at the egg surface after sperm penetration would be reflected at the physiological $\mathrm{pH}$. The energy of interaction between cell surfaces is presumed to depend in part on a repulsive force proportional to the net surface charge, and available evidence indicates that an inverse relationship exists between adhesiveness and cell surface potential (Fauré-Fremiet \& Nichita, 1929; Dan, 1947; Ambrose, James \& Lowick, 1956). The present observations, therefore, afford a reasonable, if simple correlate for the obvious lack of any attraction of motile perivitelline spermatozoa for the vitelline surface following induction of the cortical block to polyspermy. As a further correlate of this notion, it was interesting to observe that after mechanical removal of the zona pellucida with needles, the unfertilized eggs tended to stick readily to each other and to the dissecting needles. By contrast, fertilized eggs without zonae showed no such tendency to adhere.

The existence on the egg of negative surface groups remaining dissociated at pH 1.8 suggests that these might represent ionized carboxyl groups of sialic acids, which are known constituents of some cell surfaces, and have a rather low $\mathrm{p} K$ of $2 \cdot 6$ to $2 \cdot 7$. Moreover, the extinction of all negative charge at $\mathrm{pH} 1 \cdot 0$, as revealed by the total absence of surface colloid binding, appears to rule out any possible contribution by sulphate radicals, some of which would remain dissociated at $\mathrm{pH} 1 \cdot 0$. Although the charge density on the surface of the untreated egg was not significantly affected by exposure to purified neuraminidase, the charge was removed by this enzyme from both fertilized and unfertilized eggs subjected to saponification with $0 \cdot 1 \mathrm{~N}-\mathrm{KOH}$, following fixation in glutaraldehyde. The removal of this charge was clearly a specific effect of the enzyme, since control preparations showed that saponification itself did not dissipate the surface charge. The ability of purified neuraminidase to act only after saponification suggests that the sialic acid at the egg surface may be present in the $\mathcal{N}$-acetyl-O-diacetyl form, whose configuration renders the molecule resistant to neuraminidase. Only after cleavage of the $O$-acetyl linkage by saponification with $\mathrm{KOH}$ does the sialic acid moiety of this form become susceptible to the enzyme (Gibbons, 1963; Ravetto, 1968).

Nothing appears to be known of the nature of receptor sites for the plasma membrane of the fertilizing spermatozoon at the mammalian egg surface. In the light of our present results, it seems worthwhile to draw attention to recent investigations in the area of virus/cell surface interactions, which have revealed the importance of terminal sialic acids in receptor sites for adhesion and ultimate fusion of paramyxoviruses with the host cell surface (see Kohn, 1965; Okada, 1969; Howe \& Morgan, 1969). Myxoviruses will adhere readily to the mammalian sperm head (Peleg \& Ianconescu, 1966), pointing to the existence of viral receptors on the sperm surface. In this context, one wonders what relationship the diacetyl-sialic acid moiety of the egg surface might have to sperm receptor sites, to the specificity to sperm/egg fusion, and to the block to polyspermy which operates at the vitelline surface.

\section{ACKNOWLEDGMENT}

This work has been supported by NIH grant HD-03623. 
Ambrose, E. J., James, A. M. \& Lowick, J. H. B. (1956) Differences between the electrical charge carried by normal and homologous tumour cells. Nature, Lond. 177, 576.

Austin, C. R. (1968) Ultrastructure of fertilization. Holt, Rinehart \& Winston, New York.

Austin, G. R. \& Walton, A. (1960) Fertilization. In: Marshall's Physiology of Reproduction, Vol. I, part II, Chap. 10. Ed. A. S. Parkes. Longmans Green, London.

Beatty, R. A. (1957) Parthenogenesis and polyploidy in mammalian development. Cambridge University Press.

DAN, K. (1947) Electrokinetic studies on marine ova. Biol. Bull. mar. biol. Lab., Woods Hole, 93, 259.

FAURÉ-Fremiet, E. \& Nichita, G. (1927) Charge électrique et agglutination chez les amibocytes d'Invertébrés marins. Annls Physiol. Physiochim. biol. 3, 247.

Gasic, G. J., Berwick, L. \& Sorrentino, M. (1968) Positive and negative colloidal iron as cell surface electron stains. Lab. Invest. 18, 63.

Gibbons, R. A. (1963) The sensitivity of the neuraminosidic linkage in mucosubstances towards acid and towards neuraminidase. Biochem. $7.89,380$.

Howe, C. \& Morgan, G. (1969) Interactions between Sendai virus and human erythrocytes. F. Virol. 3,70 .

КонN, A. (1965) Polykaryocytosis induced by Newcastle disease virus in monolayers of animal cells. Virology, 26, 228.

Marikovsky, Y. \& DANON, D. (1969) Electron microscopic analysis of young and old red blood cells stained with colloidal iron for surface charge evaluation. F. Cell Biol. 43, 1.

Oxada, Y. (1969) Factors in fusion of cells by HVJ. Curr. Topics in Microbiol. and Immunol. 48, 102.

Peleg, B. A. \& IAnconescu, M. (1966) Spermagglutination and spermadsorption due to myxoviruses. Nature, Lond. 211, 1211.

Prko, L. (1961) La polyspermie chez les animaux. Ann. Biol. anim. Biochem. Biophys. 1, 324.

Ravetro, G. (1968) Histochemical identification of N-acetyl-O-diacetylneuraminic acid resistant to neuraminidase. 7. Histochem. Cytochem. 16, 663.

Rothschind, LoRd (1954) Polyspermy. Q. Rev. Biol. 29, 332.

Rothschild, LoRd \& SWANn, M. M. (1949) The fertilization reaction in the sea urchin egg. A propagated response to sperm attachment. F. exp. Biol. 26, 164.

Runnstrom, J. (1928) Die Veränderung der Plasmakolloide bei der Entwicklungserregung des Seeigeleies. Protoplasma, 4, 388.

Stepanini, M., OURA, C. \& Zamboni, L. (1969) Ultrastructure of fertilization in the mouse. 2. Penetration of sperm into the ovum. F. submicrosc. Cytol. $1,1$.

Szolzosi, D. (1967) Development of cortical granules and the cortical reaction in rat and hamster eggs. Anat. Rec. 159, 431.

Tyler, A., Monroy, A., KaO, C. Y. \& Grunderst, H. (1956) Membrane potential and resistance of the starfish egg before and after fertilization. Biol. Bull. mar. biol. Lab., Woods Hole, 111, 153.

Zambonr, L. (1970) Ultrastructure of mammalian oocytes and ova. Biol. Reprod., Suppl. 2, 44. 